\title{
Assessing the oxidation states and structural stability of the Ce analogue of
}

brannerite

Esther Rani Aluri, Lisa M. Bachiu, Andrew P. Grosvenor*

Department of Chemistry, University of Saskatchewan, Saskatoon, SK Canada

Scott H. Forbes, John E. Greedan

Department of Chemistry \& Chemical Biology, McMaster University, Hamilton, ON

Canada

* Author to whom correspondence should be addressed

E-mail: andrew.grosvenor@usask.ca

Phone: (306) 966-4660

Fax: (306) 966-4730 


\begin{abstract}
:
The Ce-containing analogue of brannerite (i.e., $\mathrm{UTi}_{2} \mathrm{O}_{6}$ ) was previously considered to be stoichiometric (i.e., $\mathrm{CeTi}_{2} \mathrm{O}_{6}$ ); however, it has recently been determined that the material is $\mathrm{O}$ deficient. This oxygen deficient material has been suggested to be charged balanced by the presence of a minor concentration of $\mathrm{Ce}^{3+}$ or by the A-site being cation deficient with the Ce oxidation state being 4+. A variety of Ti-containing oxides (including brannerite) have been investigated as potential nuclear wasteforms and it is necessary to understand the electronic structure of a proposed nuclear wasteform material as well as how the structure responds to radiation from incorporated waste elements. The radiation resistance of a material can be simulated by ion implantation. The objective of this study was to confirm the Ce oxidation state in the cation and oxygen deficient material (i.e., $\mathrm{Ce}_{0.94} \mathrm{Ti}_{2} \mathrm{O}_{6-\delta}$ ) and to determine how radiation damage affects this material. X-ray Photoelectron Spectroscopy (XPS) and X-ray Absorption Near-edge Spectroscopy (XANES) were used to study $\mathrm{Ce}_{0.94} \mathrm{Ti}_{2} \mathrm{O}_{6-\delta}$ before and after being implanted with $2 \mathrm{MeV}$ $\mathrm{Au}^{-}$ions. Analysis of the Ce $3 \mathrm{~d}$ XPS spectra from the as-synthesized samples using a previously developed fitting method has unequivocally shown that Ce adopts both 4+ (major) and $3+$ (minor) oxidation states, which was confirmed by examination of magnetic susceptibility data. Analysis of XPS and XANES spectra from ion implanted materials showed that both $\mathrm{Ce}$ and $\mathrm{Ti}$ were reduced as a result of radiation damage and that the local coordination environments of the cations are greatly affected by radiation damage.
\end{abstract}

Keywords: Nuclear wasteform, Brannerite, XPS, XANES, Ion implantation, XRD, Magnetic susceptibility 


\section{Introduction:}

One proposal for dealing with nuclear waste, particularly spent nuclear fuel, is to contain the waste elements (fission products and actinides) within the crystal structures of a series of metal oxides. SYNROC (synthetic rock), which contains metal oxides adopting the zirconolite, hollandite, perovskite, and rutile structures, was developed for this application. ${ }^{[1,2,5,6]}$ The majority of the materials present in SYNROC are Ti-based oxides, as a result of the ability of these materials to incorporate a wide range of waste elements in the structures that they adopt and the generally improved corrosion resistance of these materials. ${ }^{[1-9]}$ Other Ti-based mineral structures have also received attention as potential nuclear wasteforms, including the brannerite structure. ${ }^{[3-8]}$ The brannerite mineral $\left(\mathrm{UTi}_{2} \mathrm{O}_{6}\right)$ has received attention from the nuclear wasteform research community owing to the ability of this mineral to incorporate a significant amount of $U(\sim 55 \mathrm{wt} \%) .{ }^{[6]}$ The monoclinic structure of brannerite $\left(\mathrm{UTi}_{2} \mathrm{O}_{6}\right.$; space group $\left.\mathrm{C} 2 / \mathrm{m}\right)$ is presented in Fig. 1. The structure is built-up of alternating columns of $\mathrm{UO}_{6}$ octahedra and layers of $\mathrm{TiO}_{6}$ octahedra with the U-containing layer being half as dense as the Ti-containing layer. ${ }^{[7,8]}$ Chains of edge-sharing $\mathrm{UO}_{6}$ octahedra form along the b-axis. The edge-sharing $\mathrm{TiO}_{6}$ octahedra form a zigzag layer in the a/b plane and are corner sharing with the $\mathrm{UO}_{6}$ octahedra along the c-axis. ${ }^{[7,8]}$ The $\mathrm{UO}_{6}$ octahedra are regular in shape while the $\mathrm{TiO}_{6}$ octahedra are distorted in a similar fashion to those present in the anatase structure of $\mathrm{TiO}_{2}{ }^{[7,8]}$ The Ce-containing analogue of this material has been investigated for many years owing to the ease associated with dealing with a rare-earth containing material compared to an actinide containing material.

The Ce analogue of brannerite has been considered to be a stoichiometric material for many years (i.e., $\mathrm{CeTi}_{2} \mathrm{O}_{6}$ ); however, this has been called into question. ${ }^{[10-12]}$ Recent studies have suggested that this material is, in fact, oxygen deficient. (Either the ceramic method or a soft chemistry method followed by high-temperature annealing was used to produce the materials studied in these separate studies. ${ }^{[10-12]}$ ) Two reasons for the observed oxygen deficiency have been proposed in the literature. One proposal is that $\mathrm{Ce}$ has a mixture of oxidation states $(3+$ and $4+)$ with the ratio of these oxidation states varying depending on the way in which the materials are cooled after high-temperature synthesis because of the temperature dependant $\mathrm{Ce}^{3+} / \mathrm{Ce}^{4+}$ reduction-oxidation couple. ${ }^{[10]}$ 
An alternate proposal that has been presented to explain the oxygen deficiency is that the material is Ce deficient, which would require that it also be $\mathrm{O}$ deficient so as to be charged balanced. ${ }^{[11,12]}$ This second proposal has also indicated that the Ce oxidation state is fixed at 4+. ${ }^{[11,12]}$ All of the studies discussed above used (X-ray or neutron) diffraction and X-ray absorption near-edge spectroscopy (XANES) to study this material but have yielded conflicting results. ${ }^{[10-12]}$ One objective of this study has been to resolve this issue.

When selecting a material for use as a nuclear wasteform, it is important to understand how it behaves upon exposure to radiation from incorporated waste elements undergoing radioactive decay. Natural brannerite mineral samples (i.e., $\mathrm{UTi}_{2} \mathrm{O}_{6}$ ) are often found to be metamict (amorphous) because of accumulated radiation damage, which may limit the usefulness of this material as a nuclear wasteform. ${ }^{[1]}$ This being noted, studies of brannerite analogues are of interest owing to the concentration of $U$ that is found in the natural mineral. ${ }^{[6]}$ Limited information is available on the radiation tolerance of the Ce analogue of brannerite and it is necessary to understand the behaviour of this material upon exposure to radiation so as to determine if it behaves in a similar fashion to $\mathrm{UTi}_{2} \mathrm{O}_{6}$. Studying the effect of radiation-induced structural damage on materials containing an internal radiation source (e.g., Pu- or Am-substituted materials) can be difficult for a variety of reasons including: safety, availability of the radioactive element, and the ability to study these materials using a variety of techniques. These hurdles can be overcome by using simulator elements (e.g., Ce, $\mathrm{Zr}$, Gd) that mimic the chemistry of actinides and ion implantation using high-energy ion beams to study how radioactive decay damages a material. ${ }^{[9,13-15]}$ It should be recognized that although ion implantation studies do allow for the investigation of how the structure of a material is affected by radiation damage, they do not (normally) allow for a study of how the daughter products produced during radioactive decay are incorporated with the material.

The objectives of this investigation have been to resolve the question regarding the oxidation state of $\mathrm{Ce}$ in $\mathrm{Ce}_{1-\mathrm{x}} \mathrm{Ti}_{2} \mathrm{O}_{6-\delta}$ and to understand how the structure of this material is affected by radiation. The nominal formula for $\mathrm{Ce}_{1-\mathrm{x}} \mathrm{Ti}_{2} \mathrm{O}_{6-\delta}$ has been suggested to be $\mathrm{Ce}_{0.975} \mathrm{Ti}_{2} \mathrm{O}_{6-\delta}$, with the oxygen stoichiometry (i.e., 6- $\delta$ ) assumed to be 5.95 based on a fixed Ce oxidation state of 4+. ${ }^{[11]}$ In this study, a composition having the 
formula unit of $\mathrm{Ce}_{0.94} \mathrm{Ti}_{2} \mathrm{O}_{6-\delta}$ was investigated to insure that all of the $\mathrm{Ce}$ was incorporated within the brannerite structure with a trace amount of unreacted $\mathrm{TiO}_{2}$ being present. The material, once synthesized, was annealed at temperatures lower than the synthesis temperature or slow-cooled to room temperature to study the effect of temperature on the average oxidation state of Ce. Materials were also exposed to highenergy $\mathrm{Au}^{-}$ions to investigate how the structure responds to radiation. X-ray photoelectron spectroscopy (XPS) and XANES have been employed in this study to determine the average Ce oxidation state and to determine how the local structure of the ions that make up this material is affected by radiation induced damage. The results of these studies have been confirmed by the examination of powder X-ray diffraction (XRD) patterns and the collection of magnetic susceptibility data. It has been shown in this study that: (1) the average Ce oxidation state is $<4+$ in the $\mathrm{Ce}$ analogue of brannerite; (2) the average Ce oxidation state increased when the material was exposed to lower temperatures after high-temperature annealing; and (3) that radiation induced damage affects the coordination environment of the ions within the material and results in the partial reduction of both $\mathrm{Ce}$ and $\mathrm{Ti}$.

\section{Experimental:}

\subsection{Synthesis and powder $\mathrm{X}$-ray diffraction:}

The material studied (i.e., $\mathrm{Ce}_{0.94} \mathrm{Ti}_{2} \mathrm{O}_{6-\delta}$ ) was prepared using the ceramic method. Three sets of samples containing a mixture of $\mathrm{CeO}_{2}$ (Alfa Aesar; 99.9\%) and $\mathrm{TiO}_{2}$ (Alfa Aesar; $>99 \%)$ having a 0.94:2 $\left(\mathrm{CeO}_{2}: \mathrm{TiO}_{2}\right)$ molar ratio were ground using a mortar and pestle and formed into pellets using a pellet press and pressure of $6 \mathrm{MPa}$. Each pellet was placed in a tube furnace set to $600{ }^{\circ} \mathrm{C}$ and heated to $1325{ }^{\circ} \mathrm{C}$ over $8 \mathrm{hrs}$ followed by a soak at $1325{ }^{\circ} \mathrm{C}$ (in air) for 3 days, at which point the pellets were quench cooled in air, ground, pelleted and reheated in the same manner as before for another 3 days before quench cooling. After checking that the reactants had reacted as fully as possible by powder XRD using a Panalytical Empyrean instrument, some samples were ground and pelleted for further heat treatments. One set of samples was annealed at $800{ }^{\circ} \mathrm{C}$ for $40 \mathrm{hrs}$ followed by being quench cooled in air while another set of samples was first heated at $1325{ }^{\circ} \mathrm{C}$ for 1 day followed by slow cooling to room temperature (RT) over a period of $\sim 3$ days. In total, three sets of samples were produced: one that was quenched cooled 
from $1325{ }^{\circ} \mathrm{C}$ to room temperature in air; one that was annealed at $800{ }^{\circ} \mathrm{C}$ after reaction at $1325^{\circ} \mathrm{C}$; and one that was cooled slowly to RT from $1325{ }^{\circ} \mathrm{C}$. In agreement with previously reported results, each set of materials showed different colours after cooling. ${ }^{[10]}$ The samples that were quench cooled from $1325{ }^{\circ} \mathrm{C}$ were dark brown in colour while the samples that were annealed at $800{ }^{\circ} \mathrm{C}$ or slow-cooled to RT were yellow in colour (see Fig. 2). The observed differences in colour have previously been ascribed to changes in the average Ce oxidation state depending on the method used to cool the materials. ${ }^{[10]}$

High quality powder X-ray diffraction patterns were collected from representative samples using a PANalytical X'Pert Pro powder XRD equipped with a monochromatic $\mathrm{Cu} \mathrm{K}_{1} \mathrm{X}$-ray source. The powder XRD patterns were analysed by performing a Rietveld analysis using FullProf. ${ }^{[16]}$

\subsection{Ion implantation:}

The as-synthesized (i.e., quench cooled from $1325^{\circ} \mathrm{C}$ ) and slow-cooled samples of $\mathrm{Ce}_{0.94} \mathrm{Ti}_{2} \mathrm{O}_{6-\delta}$ were implanted with $2 \mathrm{MeV} \mathrm{Au}$ ions using the $1.7 \mathrm{MeV}$ Tandetron accelerator located at Interface Science Western (ISW), the University of Western Ontario. Sintered pellets of the $\mathrm{Ce}_{0.94} \mathrm{Ti}_{2} \mathrm{O}_{6-\delta}$ materials were implanted at room temperature with $2 \mathrm{MeV} \mathrm{Au}$ ions to a dose of $5 \times 10^{14}$ ions $/ \mathrm{cm}^{2}$. The ion beam was aligned normal to the pellet surface during implantation. Profiles of the ion implantation depth and the number of vacancies produced per $\mathrm{Au}^{-}$ion per nm were calculated using the Stopping and Range of Ions in Matter (SRIM-2013) software package. ${ }^{[1]}$ The ions were calculated to penetrate to a maximum depth of $\sim 800 \mathrm{~nm}$.

\subsection{XPS analysis:}

The XPS spectra from the $\mathrm{Ce}_{0.94} \mathrm{Ti}_{2} \mathrm{O}_{6-\delta}$ samples were collected using a Kratos AXIS Ultra XPS instrument equipped with a monochromatic Al Ka X-ray $(1487 \mathrm{eV})$ source that is located at Surface Science Western (SSW), the University of Western Ontario. Finely powdered samples of the as-synthesized materials were studied along with the ion-implanted pellets. Survey spectra were collected using a pass energy of 160 $\mathrm{eV}$, a step size of $0.7 \mathrm{eV}$, and an energy window of $1100-0 \mathrm{eV}$. High resolution Ce $3 \mathrm{~d}$, O 1, Ti 2p, and C 1s spectra were collected using a pass energy of $20 \mathrm{eV}$, a step size of $0.05 \mathrm{eV}$, and an appropriately sized energy window. All spectra were collected with the 
charge neutralizer turned on and were calibrated by setting the $\mathrm{C}$ 1s binding energy (BE) of adventitious $\mathrm{C}$ observed in the $\mathrm{C} 1 \mathrm{~s}$ spectra from each sample to $284.8 \mathrm{eV}$. The XPS spectra were analysed using CasaXPS. ${ }^{[18]}$

\subsection{XANES analysis:}

The Ce $\mathrm{L}_{3}$ - and Ti K-edge XANES spectra were collected using the Canadian Light Source/X-ray Science Division Collaborative Access Team (CLS@APS, Sector 20) bending magnetic beamline (20BM) located at the Advanced Photon Source (APS), Argonne National Laboratory and the Soft X-ray Microcharacterization Beamline (SXRMB, 06B1-1) located at the Canadian Light Source (CLS). ${ }^{[19,20]}$ Both beamlines employed Si (111) monochromators and provided spectra having similar resolutions. Spectra were collected from finely ground powders deposited on C tape (SXRMB) or sealed between layers of Kapton tape (20BM), and were collected in total electron yield (TEY; SXRMB), transmission (20BM), and/or partial fluorescence yield (PFY; SXRMB and 20BM) modes. All spectra were collected using an energy step size of $0.15 \mathrm{eV} / \mathrm{step}$ through the absorption edge. The Ti K-edge spectra were calibrated using Ti metal (4966 eV) and the $\mathrm{Ce} \mathrm{L}_{3}$-edge spectra were calibrated using $\mathrm{Cr}$ metal $(5989 \mathrm{eV})$.

XANES spectra were also collected from the ion-implanted pellets using the SXRMB and 20BM beamlines so as to study the effect of radiation damage on the local structure of the $\mathrm{Ce}_{0.94} \mathrm{Ti}_{2} \mathrm{O}_{6-\delta}$ materials. Spectra were collected in PFY and/or TEY mode using an energy step size of $0.15 \mathrm{eV} / \mathrm{step}$ through the absorption edge. The $\mathrm{Ce}_{\mathrm{L}}$-edge XANES spectra collected in PFY mode from the ion implanted materials were severely affected by absorption effects, so only the TEY $\mathrm{Ce} \mathrm{L}_{3}$-edge XANES spectra are reported. Absorption effects did not affect the Ti K-edge XANES spectra collected in PFY mode. All XANES spectra discussed in this contribution were analysed using the Athena software program. ${ }^{[21]}$

\subsection{Magnetic Susceptibility:}

Magnetization data were collected on a powdered sample of $\mathrm{Ce}_{0.94} \mathrm{Ti}_{2} \mathrm{O}_{6-\delta}$ using a Magnetic Property Measurement System (MPMS) from Quantum Design. The applied field was $0.1 \mathrm{~T}$ and data were taken over the temperature range of $4 \mathrm{~K}\left(-269.15^{\circ} \mathrm{C}\right)$ to $300 \mathrm{~K}\left(26.85{ }^{\circ} \mathrm{C}\right)$ in both field cooled (FC) and zero field cooled (ZFC) modes. Susceptibility data were obtained by dividing the measured magnetic moment by the 
applied field. Diamagnetic corrections were applied to the data using standard literature values. ${ }^{[22]}$

\section{Results and Discussion:}

\subsection{XRD analysis of as-synthesized materials:}

Powder XRD patterns were collected from all materials studied to confirm the presence of brannerite. Representative powder XRD patterns from $\mathrm{Ce}_{0.94} \mathrm{Ti}_{2} \mathrm{O}_{6-\delta}$ quench cooled from $1325^{\circ} \mathrm{C}$ or slow cooled to RT are presented in Fig. 3 along with the results of the Rietveld refinement of the pattern associated with the brannerite structure, which are also presented in Table 1. All patterns were observed to primarily contain the $\mathrm{Ce}$ analogue of brannerite along with a minor concentration of $\mathrm{TiO}_{2}$. This observation is consistent with the stoichiometry used to form these materials (i.e., $\mathrm{Ce}_{0.94} \mathrm{Ti}_{2} \mathrm{O}_{6-\delta}$ ), as it has been determined previously that $\mathrm{Ce}_{0.975} \mathrm{Ti}_{2} \mathrm{O}_{6-\delta}$ is the most likely composition for this material. ${ }^{[11]}$ A slight excess of $\mathrm{TiO}_{2}$ was purposefully used during the synthesis of these materials to make sure that no $\mathrm{CeO}_{2}$ remained after heating, as the focus of this study was to identify how the Ce oxidation state changes in brannerite depending on the cooling method used after high-temperature annealing. The results of the Rietveld refinements (Fig. 3 and Table 1) are consistent with previously reported results for these materials. ${ }^{[11,12]}$

\subsection{XANES and XPS analysis of the as-synthesized materials:}

\subsubsection{Ce $L_{3}$-edge $X A N E S$ spectra:}

$\mathrm{Ce}_{3}$-edge XANES spectra were collected from the as-synthesized brannerite materials (Fig. 4a) and result from the excitation of $2 p$ electrons to $5 \mathrm{~d}$ states with the lineshape of the spectrum from $\mathrm{Ce}^{3+}$ being considerably different than the spectrum from $\mathrm{Ce}^{4+} \cdot{ }^{[23-25]}$ Four features are observed in spectra from $\mathrm{Ce}^{4+}$-containing materials (labelled as $\mathrm{B}_{1}, \mathrm{~B}_{2}, \mathrm{~B}_{3}$, and $\mathrm{B}_{4}$ in Fig. $4 \mathbf{a}$ ) because of a pre-edge, quadrupolar $2 \mathrm{p} \rightarrow 4 \mathrm{f}$ transition $\left(\mathrm{B}_{1}\right)$, and three dipolar, $2 \mathrm{p} \rightarrow 5 \mathrm{~d}$ transitions resulting from changes in the $\mathrm{Ce} 4 \mathrm{f}$ final-state occupancies $\left(4 \mathrm{f}^{2}\left(\mathrm{~B}_{2}\right), 4 \mathrm{f}^{1}\left(\mathrm{~B}_{3}\right)\right.$, and $\left.4 \mathrm{f}^{0}\left(\mathrm{~B}_{4}\right)\right) \cdot{ }^{[24,25]}$ The excitation of a $2 \mathrm{p}$ electron from

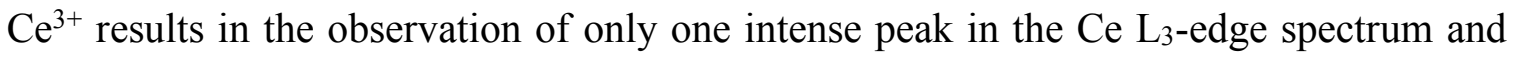
has a similar energy to feature $\mathrm{B}_{2}$ in the spectrum from $\mathrm{Ce}^{4+} \cdot{ }^{[10]}$

The spectral lineshapes observed in Fig. 4a have been used in the past to argue for the presence of only $\mathrm{Ce}^{4+}$ in these materials owing to the similarity of these spectra to 
those from materials that exclusively contain $\mathrm{Ce}^{4+} \cdot{ }^{41,12]}$ However, closer inspection of the spectra shows that there is a slight difference in the intensity of feature $\mathrm{B}_{2}$ when comparing the material quench cooled from $1325{ }^{\circ} \mathrm{C}$ vs. the material that was slowcooled to RT after high-temperature annealing (Fig. 4a). It is argued here that this difference is a result of the presence of more $\mathrm{Ce}^{3+}$ in the quench cooled sample. A linear combination fitting was performed on the spectrum from the quench cooled sample using $\mathrm{CePO}_{4}\left(\mathrm{Ce}^{3+}\right)$ and the slow-cooled $\mathrm{Ce}_{0.94} \mathrm{Ti}_{2} \mathrm{O}_{6-\delta}$ sample as standards. As is shown in Fig. $\mathbf{4 b}$, the spectrum from the quench cooled sample is reproduced when a combination of the two standard spectra are used that contains $\sim 7 \%$ of the $\mathrm{Ce}^{3+}$ standard. It should be noted that this analysis only provides the relative difference in the $\left[\mathrm{Ce}^{3+}\right]$ between the two samples and not the absolute $\left[\mathrm{Ce}^{3+}\right]$ in each sample.

\subsubsection{Ce 3d XPS spectra:}

It has been demonstrated previously that both $\mathrm{Ce}_{4,5}$-edge XANES spectra and Ce 3d XPS spectra, which both result from the excitation of Ce $3 \mathrm{~d}$ electrons, are highly sensitive to changes in the Ce oxidation state. ${ }^{[10,26]}$ This increased sensitivity is a result of the greater resolution of these spectra compared to the resolution of $\mathrm{Ce}_{2}$-edge XANES spectra. Ce 3d XPS spectra have been collected in the present study to better understand the oxidation state of $\mathrm{Ce}$ in the as-synthesized brannerite materials and to settle the question regarding the presence of $\mathrm{Ce}^{3+}$ in these materials. Ce $3 \mathrm{~d}$ XPS spectra from $\mathrm{CePO}_{4}$ and $\mathrm{CeO}_{2}$ are presented in Fig. 5 to show the significant spectral differences observed when studying $\mathrm{Ce}^{3+}$ - or $\mathrm{Ce}^{4+}$-containing materials. The reasons for the different features present in the spectra have been discussed in detail previously along with the method used to fit these spectra (see Fig. 5); however, a short description is provided here. ${ }^{[26]}$ Eight peaks were used to fit the spectrum from $\mathrm{CeO}_{2}$, which may also contain traces of $\mathrm{Ce}^{3+}$ as a result of surface defects. The multiple components representing the spin-orbit split peaks result from the different $\mathrm{Ce} 4 \mathrm{f}$ occupancies in the final state $\left(4 \mathrm{f}^{0,1,2}\right)$ along with the presence of satellite peaks. ${ }^{[27]}$ The Ce $3 \mathrm{~d}$ XPS spectrum from $\mathrm{CePO}_{4}$, however, only contains two pairs of spin-orbit split peaks. The spectra have been fitted with pairs of peaks with the lowest binding energy peak representing the core-line and the corresponding higher binding energy peak representing a shake-up satellite peak. The $\mathrm{Ce}$ $3 \mathrm{~d}_{5 / 2}$ components have been labeled as $\mathrm{v}$ and $\mathrm{u}$, referring to the $\mathrm{Ce}^{4+}$ and $\mathrm{Ce}^{3+}$ 
components, respectively, while the Ce $3 \mathrm{~d}_{3 / 2}$ components have been labeled as v' and $\mathrm{u}$ '. The integrated peak areas of the fitted component peaks were used to calculate the relative $\left[\mathrm{Ce}^{3+}\right]$ in the brannerite samples. ${ }^{[28]}$ The spectra presented in Fig. $\mathbf{5}$ are consistent with those reported previously. ${ }^{[26]}$

The Ce $3 \mathrm{~d}$ XPS spectra from the three $\mathrm{Ce}_{0.94} \mathrm{Ti}_{2} \mathrm{O}_{6-\delta}$ materials studied here are presented in Fig. 6 and were fitted to determine if $\mathrm{Ce}^{3+}$ was present. When compared to the spectra presented in Fig. 5, it can be seen that the spectra from $\mathrm{Ce}_{0.94} \mathrm{Ti}_{2} \mathrm{O}_{6-\delta}$ contain features representing $\mathrm{Ce}^{4+}$ (major) and $\mathrm{Ce}^{3+}$ (minor). The spectra were fitted using the method described above (and elsewhere) to determine the $\mathrm{Ce}^{3+}: \mathrm{Ce}^{4+}$ ratios. ${ }^{[26]}$ The results of the fittings are presented in Table 2. The $\mathrm{Ce}_{0.94} \mathrm{Ti}_{2} \mathrm{O}_{6-\delta}$ sample that was analysed after being quench-cooled from $1325^{\circ} \mathrm{C}$ was observed to contain the highest concentration of $\mathrm{Ce}^{3+}\left(\sim 41 \% \mathrm{Ce}^{3+}\right)$, followed by the sample that was quench-cooled and then postannealed at $800{ }^{\circ} \mathrm{C}\left(\sim 34 \% \mathrm{Ce}^{3+}\right)$, and finally the sample that was slow-cooled to RT after high-temperature annealing at $1325{ }^{\circ} \mathrm{C}\left(\sim 32 \% \mathrm{Ce}^{3+}\right)$. The difference in the amount of $\mathrm{Ce}^{3+}$ present in the quech-cooled sample vs. the slow-cooled sample $\left(\sim 9 \% \mathrm{Ce}^{3+}\right)$ is

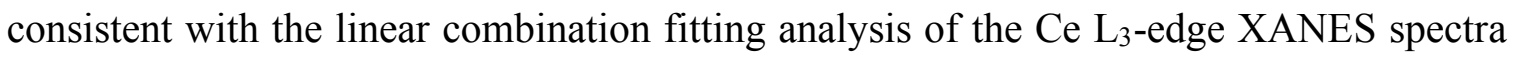
discussed above $\left(\sim 7 \% \mathrm{Ce}^{3+}\right.$; cf. Fig. 4). This analysis confirms the previously reported conclusion that $\mathrm{Ce}^{3+}$ is present in the Ce-analogue of brannerite. ${ }^{[10]}$

\subsubsection{Ti K-edge XANES spectra:}

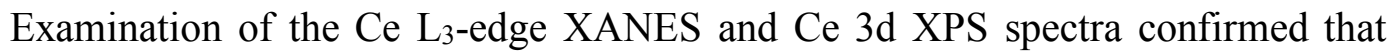
the Ce-analogue of brannerite contains $\mathrm{Ce}^{3+}$ (along with $\mathrm{Ce}^{4+}$ ), which would require the material to be O-deficient. As such, it would be expected that the average Ti coordination number $(\mathrm{CN})$ would be less than the nominal value of 6 observed in the structure of the U-containing material $\left(\mathrm{UTi}_{2} \mathrm{O}_{6}\right)$, and that the $\mathrm{CN}$ would change depending on how the material was cooled after high-temperature annealing.

Ti K-edge XANES spectra are sensitive to changes in $\mathrm{Ti} \mathrm{CN}$, and result from $1 \mathrm{~s} \rightarrow 3 \mathrm{~d}$ (pre-edge) and $1 \mathrm{~s} \rightarrow 4 \mathrm{p}$ (main-edge) transitions, with the pre-edge region being particularly sensitive to changes in $\mathrm{CN}^{[29-31]}$ These XANES spectra follow dipole selection rules (i.e., $\Delta \mathrm{l}=+/-1$ ); however, quadrupolar transitions (e.g., $1 \mathrm{~s} \rightarrow 3 \mathrm{~d}$ ) can also be observed, although they are generally weak when compared to dipolar transitions (e.g., $1 \mathrm{~s} \rightarrow 4 \mathrm{p}$ ). As the $\mathrm{CN}$ decreases from 6 , increased orbital overlap will occur between Ti 3d 
and $\mathrm{Ti} 4 \mathrm{p}$ states, resulting in an increased dipolar character (and therefore intensity) of the of the pre-edge region. ${ }^{[29,31-33]}$

The Ti K-edge XANES spectra from $\mathrm{Ce}_{0.94} \mathrm{Ti}_{2} \mathrm{O}_{6-\delta}$ quench-cooled from $1325{ }^{\circ} \mathrm{C}$, annealed at $800{ }^{\circ} \mathrm{C}$ after high-temperature annealing, or slow-cooled to RT from $1325^{\circ} \mathrm{C}$ are presented in Fig. 7 with the appropriate excitations labelled. The Ti K-edge spectra from all three samples have lineshapes that would be expected for $\mathrm{Ti}^{4+}$ ions in a near 6coordinate environment; however, the pre-edge peak intensities are greater than would be expected for $\mathrm{Ti}^{4+}$ in ordered 6-coordinate environments as a result of the distortion of the Ti-O coordination environment in the brannerite structure and the lower, average Ti CN as a result of the O-deficiency. What is clearly obvious from the spectra is the lack of differences observed between the spectra regardless of the method used to cool these materials. The differences in the $\mathrm{Ce}^{3+}: \mathrm{Ce}^{4+}$ ratio present in the quench cooled sample vs. the slow cooled sample (Table 2) would result in an increased O-deficiency in the quench cooled sample compared to the other materials and a reduced, average Ti CN. Stennett et al. found through analysis of neutron powder diffraction data that the $\mathrm{Ce}$ cation deficiency in these materials is balanced by deficiency in the $\mathrm{O}$ site that connects the Ti-O and Ce-O coordination environments, which are both nominally 6-coordinate in the brannerite $\left(\mathrm{UTi}_{2} \mathrm{O}_{6}\right)$ structure. ${ }^{[11]}$ The lack of variation observed in the Ti K-edge XANES structure from the Ce analogue of brannerite when quench-cooled vs. annealing at lower temperatures after high-temperature heating may be explained by studying the structure. ${ }^{[10,11]}$ Three non-equivalent $\mathrm{O}$ sites are present within the brannerite structure. Two of these sites contain $\mathrm{O}$ ions that interact with both $\mathrm{Ce}$ and $\mathrm{Ti}$ while the third site contains $\mathrm{O}$ ions located between $\mathrm{Ti}$ atoms within the zigzag layer of $\mathrm{TiO}_{6}$ octahedra. ${ }^{[11,34]}$ This later $\mathrm{O}$ site only coordinates to $\mathrm{Ti}$ atoms and accounts for three of the six $\mathrm{O}$ atoms in each $\mathrm{TiO}_{6}$ octahedra. ${ }^{[34]}$ As such, it appears that the changing $\mathrm{O}$ deficiency observed in these materials depending on cooling conditions does not significantly affect the average Ti CN, leading to the observation of very little change in the Ti K-edge XANES spectra despite the differences observed in the Ce $3 \mathrm{~d}$ XPS and Ce $\mathrm{L}_{3}$-edge XANES spectra. This being stated, higher resolution Ti K-edge (or Ti L2,3-edge) XANES spectra may yield more insight. 


\subsection{Magnetic properties of the as-synthesized materials:}

The Ce $3 \mathrm{~d}$ XPS spectra collected from powders of the $\mathrm{Ce}_{0.94} \mathrm{Ti}_{2} \mathrm{O}_{6-\delta}$ materials clearly indicated the presence of $\mathrm{Ce}^{3+}$ in these materials; however, one could argue that surface defects could be responsible for the presence of $\mathrm{Ce}^{3+}$ owing to the surface sensitivity of XPS, and that the calculated $\mathrm{Ce}^{3+}$ concentration does not properly reflect the true $\mathrm{Ce}^{3+}$ concentration present in the bulk material. This could also be proposed as the reason for why no variations in the Ti K-edge XANES spectra were observed. Magnetic susceptibility data were collected to confirm the presence of $\mathrm{Ce}^{3+}$ in the $\mathrm{Ce}_{0.94} \mathrm{Ti}_{2} \mathrm{O}_{6-\delta}$ sample that was post-annealed at $800{ }^{\circ} \mathrm{C}$ after being synthesized at $1325{ }^{\circ} \mathrm{C}$ followed by quench cooling (see Fig. 8). The sample was observed to be strongly paramagnetic, which must be attributed to significant levels of $\mathrm{Ce}^{3+}$ being present in the bulk of the material. A plot of the inverse susceptibility (see inset in Fig. 8) shows a reasonable adherence to the Curie-Weiss law (Eq.1) above $220 \mathrm{~K}\left(-53.15{ }^{\circ} \mathrm{C}\right)$. The magnetic susceptibilities of $\mathrm{Ce}^{3+}$ compounds are strongly influenced by crystal field effects as the separation between the crystal field split states is of the order of $\sim 100 \mathrm{~K}$ ($173.15^{\circ} \mathrm{C}$ ) and only at higher temperatures is the Curie-Weiss law obtained. The Curie constant $(\mathrm{C})$ obtained from this fit is $0.285(3)(\mathrm{emu} / \mathrm{mole}) \mathrm{K}$. The expected $\mathrm{C}$ value would be $0.804 \times 0.94=0.756(\mathrm{emu} / \mathrm{mole}) \mathrm{K}$ if all $\mathrm{Ce}$ cations present were $\mathrm{Ce}^{3+}$. Thus, the atomic percent of $\mathrm{Ce}^{3+}$ in this sample is $\sim 38 \%$, which is in reasonable agreement with the value obtained from analysis of the Ce $3 \mathrm{~d}$ XPS spectrum from this sample $\left(\sim 34 \% \mathrm{Ce}^{3+}\right)$. Fits using slightly different temperature intervals gave similar values for $\mathrm{C}$ to within $\sim 5 \%$, which is a reasonable error to assign to the $\left[\mathrm{Ce}^{3+}\right]$ obtained by this particular method.

$$
\chi=\mathrm{C} /(\mathrm{T}-\theta)
$$

\subsection{Examination of ion-implanted $\mathrm{Ce}_{0.94} \mathrm{Ti}_{2} \mathrm{O}_{6-\delta}$ :}

The development of materials (crystalline or amorphous) for the safe sequestration of nuclear waste requires knowledge of how these (and related) materials will be affected by the radioactive decay of incorporated waste elements. The materials studied here were implanted with $2 \mathrm{MeV} \mathrm{Au}$ ions to a dose of $5 \times 10^{14}$ ions $/ \mathrm{cm}^{2}$ followed 
by XANES and XPS analysis to study if the procedure used to cool the materials influenced the response of these materials to radiation.

\subsubsection{Ce $3 d$ and Ti 2p XPS analysis:}

XPS spectra were collected to understand how the surface chemistry of these materials was affected by ion implantation. The Ce $3 \mathrm{~d}$ and Ti 2p XPS spectra from the $\mathrm{Ce}_{0.94} \mathrm{Ti}_{2} \mathrm{O}_{6-\delta}$ materials that were slow-cooled to $\mathrm{RT}$ after annealing at $1325{ }^{\circ} \mathrm{C}$ are presented in Fig. 9 and have been compared to the corresponding spectra from the assynthesized material. Examination of the Ce 3d XPS spectrum from the ion-implanted material shows a clear difference in lineshape compared to the spectrum from the assynthesized material, with the former spectrum more resembling that of $\mathrm{Ce}^{3+}$ than $\mathrm{Ce}^{4+}$ (cf. Fig. 9a). Fitting of the Ce 3d XPS spectrum from the ion-implanted material gives a $\mathrm{Ce}^{3+}: \mathrm{Ce}^{4+}$ ratio of $69: 31$, which is significantly different than the ratio determined for the as-synthesized material (32:68). It is known that low energy $(\mathrm{KeV})$ ion sputtering of $\mathrm{Ce}$ containing surfaces can result in the reduction of $\mathrm{Ce}^{4+}$ to $\mathrm{Ce}^{3+}$, and the observation reported above was expected considering that the materials were implanted with $2 \mathrm{MeV}$ $\mathrm{Au}^{-}$ions. ${ }^{[35,36]}$

The Ti 2p XPS spectra from the ion implanted samples are presented in Fig. 9b and have been normalized to show the differences in linewidth between the spectra collected from the as-synthesized material vs. the ion-implanted material. Both spectra show $2 p_{3 / 2}$ and $2 p_{1 / 2}$ spin orbit split peaks that are relatively narrow owing to the lack of multiplet splitting observed in spectra that (primarily) contain $\mathrm{Ti}^{4+}$. The binding energy of the Ti $2 p_{3 / 2}$ peak in the spectrum from the as-synthesized material $(458.2 \mathrm{eV})$ is in agreement with previously reported values for $\mathrm{Ti}^{4+} \cdot{ }^{[37]}$ After ion-implantation, the resulting spectrum was found to be broader to lower binding energy (compared to the spectrum from the as-synthesized material), which is considered to be a result of the partial reduction of Ti. It was found that two peaks were required to properly fit each spin-orbit split feature in the Ti $2 p$ XPS spectrum from the ion-implanted material (not shown), with the higher binding energy ( $2 \mathrm{p}_{3 / 2}$ or $2 \mathrm{p}_{1 / 2}$ ) peak corresponding to $\mathrm{Ti}^{4+}$ and the lower binding energy $\left(2 \mathrm{p}_{3 / 2}\right.$ or $\left.2 \mathrm{p}_{1 / 2}\right)$ peak corresponding to $\mathrm{Ti}^{3+}$. The $\mathrm{Ti}^{4+}: \mathrm{Ti}^{3+}$ ratio was observed to be $\sim 82: 18$; however, this ratio changed considerably if the peak widths were allowed to vary. 


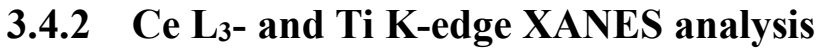

The XPS spectra presented above only allowed for a study of how the surface regions of the pellets of these materials were affected by ion-implantation. Hard X-ray XANES spectra are inherently more bulk-sensitive than XPS spectra and are more sensitive to changes in the local coordination environments of the ions under investigation. Both Ti K-edge and Ce $\mathrm{L}_{3}$-edge XANES spectra were collected from the ion-implanted pellets to study how ion implantation affected the sub-surface region of these materials, as well as the local coordination environment of $\mathrm{Ti}$.

The Ce $\mathrm{L}_{3}$-edge XANES spectrum from a pellet of $\mathrm{Ce}_{0.94} \mathrm{Ti}_{2} \mathrm{O}_{6-\delta}$ that was slowcooled to RT after annealing at $1325{ }^{\circ} \mathrm{C}$ followed by ion-implantation is presented in Fig. 10 along with the spectrum from the as-synthesized material. The lineshape of the spectrum from the ion-implanted material is considerably different to the spectrum from the as-synthesized material and closely resembles previously reported spectra from $\mathrm{CeO}_{x}$ $\mathrm{TiO}_{2}$ materials that contained a significant concentration of $\mathrm{Ce}^{3+}$ (along with $\left.\mathrm{Ce}^{4+}\right) .{ }^{[38]}$ The identification of $\mathrm{Ce}^{3+}$ in the $\mathrm{Ce}_{3}$-edge XANES spectrum is in agreement with the analysis of the Ce 3d XPS spectra discussed in Section 3.4.1.

The Ti K-edge XANES spectra from the ion-implanted pellets of $\mathrm{Ce}_{0.94} \mathrm{Ti}_{2} \mathrm{O}_{6-\delta}$ that were slow-cooled to RT after annealing at $1325{ }^{\circ} \mathrm{C}$ or quench-cooled in air from $1325{ }^{\circ} \mathrm{C}$ are presented in Fig. 11 along with the spectrum the as-synthesized material (slow-cooled to RT after annealing at $1325^{\circ} \mathrm{C}$ ). In comparison to the as-synthesized material, the spectra from the ion-implanted materials show a decrease in energy and intensity of the main-edge region and an increase in the intensity of the pre-edge region. These changes are indicative of a decrease in the local coordination environment of the $\mathrm{Ti}$ ions as a result of disordering of the anion (and cation) lattice(s) during ionimplantation. ${ }^{[15,39]}$ These spectral differences indicate that the brannerite structure is damaged by ion-implantation, which simulates the effect of decay of incorporated radioactive elements. It should be noted that little to no difference was observed between the Ti K-edge XANES spectra collected from the ion-implanted materials that received different cooling treatments and, therefore, contained different proportions of $\mathrm{Ce}^{3+}$ and $\mathrm{Ce}^{4+}$ (and $\mathrm{O}$ vacancies) prior to ion-implantation. 


\section{Conclusions}

The study of the $\mathrm{Ce}$ analogue of brannerite has confirmed that this material is cation and anion deficient and that it contains both $\mathrm{Ce}^{3+}$ and $\mathrm{Ce}^{4+}$. Further, it has been shown here that the $\mathrm{Ce}^{3+}: \mathrm{Ce}^{4+}$ ratio in these materials varies depending on the way in which the materials are cooled post synthesis. Finally, examination of XPS and XANES spectra from the ion-implanted materials indicated that radioactive decay of incorporated nuclear waste elements will affect both the surface and sub-surface region of this material and that the method used to cool the materials did not appear to affect the response of this material to radiation. Although $\mathrm{Ce}$ is an insufficient analogue for $\mathrm{U}$, it does behave in a very similar fashion to $\mathrm{Pu}$, which can also exhibit an oxidation state of $3+.{ }^{[8,23]}$ Changes in the chemistry of these materials as a result of the decay of incorporated radioactive elements during nuclear waste sequestration could affect how they behave if exposed to aqueous environments. Future studies of these materials should examine how the leachability of these materials changes depending on the average Ce oxidation state.

\section{Acknowledgements:}

This project was funded by the Natural Sciences and Engineering Research Council (NSERC) of Canada through a Discovery grant awarded to APG. Mr. Jack Hendriks is thanked for carrying out the ion implantation studies using the Tandetron accelerator located at Interface Science Western, University of Western Ontario. Dr. Mark Biesinger is thanked for help in collection of the XPS spectra using the facilities located at Surface Science Western, University of Western Ontario. Dr. Paul Dube, Brockhouse Institute for Materials Research, McMaster University, is thanked for performing the magnetic susceptibility measurements. Dr. Zou Finfrock and Dr. Matthew Ward are thanked for their help in carrying out XANES measurements using the 20BM beamline (CLS@APS). The CLS@APS facilities are supported by the US Department of Energy-Basic Energy Sciences and the Canadian Light Source (CLS). Dr. Yongfeng $\mathrm{Hu}$ and Ms. Aimee Maclennan are thanked for their support in carrying out XANES experiments using the SXRMB (06B1-1) beamline located at the CLS. The CLS

is supported by the Canada Foundation for Innovation, the Natural Sciences and Engineering Research Council, Western Economic Diversification Canada, the National Research Council of Canada, the Canadian Institutes of Health Research, the Government 
of Saskatchewan, and the University of Saskatchewan. APG congratulates SSW on 35 year of performing excellent surface science research and education. 


\section{References:}

[1] R. C. Ewing, W. J. Weber, F. W. Clinard Jr., Prog. Nucl. Energy 1995; 29, 63.

[2] A. E. Ringwood, S. E. Kesson, N. G. Ware, W. Hibberson, A. Major, Nature 1979; 278, 219.

[3] M. James, M. L. Carter, J. N. Watson, J. Solid State Chem. 2003; 174, 329.

[4] M. H. Donaldson, R. Stevens, B. E. Lang, J. Boerio-Goates, B. F. Woodfield, R. L. Putnam, A. Navrotsky, J. Therm. Anal. Calorim. 2005; 81, 617.

[5] J. Lian, L. M. Wang, G. R. Lumpkin, R. C. Ewing, Nucl. Instrum. Methods Phys. Res., Sect. B 2002; 191, 565.

[6] M. Colella, G. R. Lumpkin, Z. Zhang, E. C. Buck, K. L. Smith, Phys. Chem. Minerals 2005; 32, 52.

[7] G. R. Lumpkin, K. L. Smith, M. G. Blackford, J. Nucl. Mater. 2001; 289, 177.

[8] K. B. Helean, A. Navrotsky, G. R. Lumpkin, M. Colella, J. Lian, R. C. Ewing, B. Ebbinghaus, J. G. Catalano J. Nucl. Mater. 2003; 320, 231.

[9] R. C. Ewing, W. J. Weber, J. Lian J. Appl. Phys. 2004; 95, 5949.

[10] L. T. Huynh, S. B. Eger, J. D. S. Walker, J. R. Hayes, M. W. Gaultois, A. P. Grosvenor Solid State Sci. 2012; 14, 761.

[11] M. C. Stennett, C. L. Freeman, A. S. Gandy, N. C. Hyatt, J. Solid State Chem. 2012; $192,172$.

[12] L. Kong, D. J. Gregg, I. Karatchevtseva, Z. Zhang, M. G. Blackford, S. C. Middleburgh, G. R. Lumpkin, G. Triani Inorg. Chem. 2014; 53, 6561.

[13] J. Lian, K. B. Helean, B. J. Kennedy, L. M. Wang, A. Navrotsky, R. C. Ewing J. Phys. Chem. B 2006; 110, 2343.

[14] S. X. Wang, L. M. Wang, R. C. Ewing, G. S. Was, G. R. Lumpkin Nucl. Instrum. Methods. Phys. Rec., Sect. B 1999; 148, 704.

[15] E. R. Aluri, J. R. Hayes, J. D. S. Walker, A. P. Grosvenor J. Phys. Chem. C 2014; 118,7910 .

[16] J. Carvajal-Rodríguez Physica B 1993; 192, 55.

[17] J.F. Ziegler, J.P. Biersack, M.D. Ziegler, SRIM (The Stopping and Range of Ions in Solids)-2013, MD: USA, 2013. 
[18] N. Fairley, CasaXPS, Version 2.3.16; Casa Software Ltd., Teighnmouth, Devon, U.K., 2003. www.casaxps.com.

[19] S.M. Heald, D.L. Brewe, E.A. Stern, K.H. Kim, F.C. Brown, D.T. Jiang, E.D. Crozier, R.A. Gordon J. Synchrotron Radiat. 1999; 6, 347.

[20] Y. F. Hu, I. Coulthard, D. Chevrier, G. Wright, R. Igarashi, A. Stinikov, B. W. Yates, E. L. Hallin, T. K. Sham, R. Reininger AIP Conf. Proc. 2010; 1234, 343.

[21] B. Ravel, M. Newville J. Synchrotron Radiat. 2005; 12, 537.

[22] P.W. Selwood, Magnetochemistry, Interscience Publishers, New York, 1956.

[23] C. Lopez, X. Deschanels, J.M. Bart, J.M. Boubals, C. Den Auwer, E. Simoni J. Nucl. Mater. 2003; 312, 76.

[24] P. Nachimuthu, W.-C. Shih, R.-S. Liu, L.-Y. Jang, J.-M. Chen J. Solid State Chem. 2000; $149,408$.

[25] A. Kotani, K.O. Kvashnina, S.M. Butorin, P. Glatzel J. Electron. Spectrosc. Rel.

Phenom. 2001; 184, 210.

[26] M. N. Revoy, R. W. J. Scott, A. P. Grosvenor J. Phys. Chem. C, 2013; 117, 10095.

[27] G. Kaindl, G. K. Wertheim, G. Schmiester, E. V. Sampathkumaran Phys. Rev. Lett. $1987 ; 58,606$.

[28] F. Larachi, J. Pierre, A. Adnot, A. Bernis Appl. Surf. Sci. 2002; 195, 236.

[29] T. Yamamoto X-Ray Spectrom. 2008; 37, 572.

[30] L.A. Grunes Phys. Rev. B 1983; 27, 2111.

[31] M.W. Gaultois, A.P. Grosvenor J. Mater. Chem. 2011; 21, 1829.

[32] D. Cabaret, A. Bordage, A. Juhin, M. Arfaoui; E. Gaudry Phys. Chem. Chem. Phys. 2010; $12,5619$.

[33] F. Farges, G. E. Brown, J. J. Rehr Phys. Rev. B 1997; 56, 1809.

[34] J. T. Szymański, J. D. Scott Can. Mineral. 1982; 20, 271.

[35] A. Pfau, K. D. Schierbaum Surf. Sci. 1994; 321, 71.

[36] M. Krawczyk, M. Holdynski, W. Lisowski, J. W. Sobczak, A. Jablonski Appl. Surf. Sci. 2015; 341, 196.

[37] C. D. Wagner, A. V. NAumkin, A. Kraut-Vass, J. W. Allison, C. J. Powell, J. R. Rumble, Jr. NIST Standard Reference Database, Version 3.4 (web version), htttp://srdata.nist.gov/xps/, 2003. 
[38] K. A. Michalow-Mauke, Y. Lu, K. Kowalski, T. Graule, M. Nachtegaal, O. Kröcher, D. Ferri ACS Catal. 2015; 5, 5657.

[39] E. R. Aluri, A. P. Grosvenor J. Alloys Compd. 2014; 616, 516. 


\section{Tables:}

Table 1: Refined unit cell parameters for $\mathrm{Ce}_{0.94} \mathrm{Ti}_{2} \mathrm{O}_{6-\delta}$ from the Rietveld analysis of powder XRD data

\begin{tabular}{|c|c|c|}
\hline & $\begin{array}{l}\mathrm{Ce}_{0.94} \mathrm{Ti}_{2} \mathrm{O}_{6-\delta} \\
\text { Quench cooled }\end{array}$ & $\begin{array}{l}\mathrm{Ce}_{0.94} \mathrm{Ti}_{2} \mathrm{O}_{6-\delta} \\
\text { Slow cooled to } \mathrm{RT}\end{array}$ \\
\hline a $(\AA)$ & $9.8266(2)$ & $9.8308(2)$ \\
\hline b $(\AA)$ & $3.75253(7)$ & $3.7550(1)$ \\
\hline c (A) & $6.8849(1)$ & $6.8979(2)$ \\
\hline$\beta\left(^{0}\right)$ & $119.2248(6)$ & $119.2018(7)$ \\
\hline
\end{tabular}


Table 2: $\mathrm{Ce}^{4+}$ and $\mathrm{C}^{3+}$ concentrations in $\mathrm{Ce}_{0.94} \mathrm{Ti}_{2} \mathrm{O}_{6-\delta}$ as determined by fitting of $\mathrm{Ce}$ 3d XPS spectra

\begin{tabular}{|c|c|c|c|}
\hline & $\begin{array}{l}\mathrm{Ce}_{0.94} \mathrm{Ti}_{2} \mathrm{O}_{6-\delta} \\
\text { Quench cooled }\end{array}$ & $\begin{array}{l}\mathrm{Ce}_{0.94} \mathrm{Ti}_{2} \mathrm{O}_{6-\delta} \\
\text { Annealed at } 800{ }^{\circ} \mathrm{C}\end{array}$ & $\begin{array}{l}\mathrm{Ce}_{0.94} \mathrm{Ti}_{2} \mathrm{O}_{6-\delta} \\
\text { Slow cooled to } \mathrm{RT}\end{array}$ \\
\hline$\left[\mathrm{Ce}^{4+}\right]$ & $59 \%$ & $66 \%$ & $68 \%$ \\
\hline$\left[\mathrm{Ce}^{3+}\right]$ & $41 \%$ & $34 \%$ & $32 \%$ \\
\hline
\end{tabular}




\section{Figure captions:}

Figure 1: A representation of the brannerite structure $\left(\mathrm{UTi}_{2} \mathrm{O}_{6}\right)$ is shown looking down the b-axis.

Figure 2: An image showing how the colour of the Ce-analogue of brannerite varies depending on the cooling method used during the synthesis of the material is shown. The quench cooled sample is presented on the left while the sample that was slow cooled to $\mathrm{RT}$ is presented on the right.

Figure 3: The experimental powder XRD patterns and corresponding Rietveld refinement results are shown for (a) the quench cooled $\mathrm{Ce}_{0.94} \mathrm{Ti}_{2} \mathrm{O}_{6-\delta}$ sample and (b) the $\mathrm{Ce}_{0.94} \mathrm{Ti}_{2} \mathrm{O}_{6-\delta}$ sample that was slow cooled to RT.

Figure 4: The normalized Ce $\mathrm{L}_{3}$-edge XANES spectra from samples that were either quench cooled or slow cooled to RT are presented in (a). The results of a linear combination fitting of the quench cooled sample is presented in (b) along with the weighed standard spectra used to fit this spectrum.

Figure 5: The fitted $\mathrm{Ce} 3 \mathrm{~d}$ XPS spectra from (a) $\mathrm{CeO}_{2}$ and (b) $\mathrm{CePO}_{4}$ are shown.

Figure 6: The fitted Ce $3 \mathrm{~d}$ XPS spectra from the $\mathrm{Ce}_{0.94} \mathrm{Ti}_{2} \mathrm{O}_{6-\delta}$ materials that were (a) quench cooled from $1325{ }^{\circ} \mathrm{C}$, (b) annealed at $800{ }^{\circ} \mathrm{C}$ followed by quench cooling, or (c) slow cooled from $1325^{\circ} \mathrm{C}$ to RT are shown.

Figure 7: The Ti K-edge XANES spectra from the $\mathrm{Ce}_{0.94} \mathrm{Ti}_{2} \mathrm{O}_{6-\delta}$ materials that were quench cooled from $1325{ }^{\circ} \mathrm{C}$, annealed at $800{ }^{\circ} \mathrm{C}$ followed by quench cooling, or slow cooled from $1325^{\circ} \mathrm{C}$ to RT are compared. The pre-edge (1s $\left.\rightarrow 3 \mathrm{~d}\right)$ and main-edge (1s $\rightarrow$ 4 p) transitions are labelled. 
Figure 8: The magnetic susceptibility of $\mathrm{Ce}_{0.94} \mathrm{Ti}_{2} \mathrm{O}_{6 . \delta}$ that was annealed at $800{ }^{\circ} \mathrm{C}$ post synthesis is shown. The inset shows a fit to the Curie-Weiss law (Eq. 1) above 200K. The small anomaly observed in the $\mathrm{ZFC}$ data near $50 \mathrm{~K}$ is due to the melting of solid $\mathrm{O}_{2}$.

Figure 9: The (a) Ce $3 d$ and (b) Ti $2 p$ XPS spectra from the ion-implanted $\mathrm{Ce}_{0.94} \mathrm{Ti}_{2} \mathrm{O}_{6-\delta}$ material that was slow cooled from $1325{ }^{\circ} \mathrm{C}$ to RT are shown and are compared to the corresponding spectra from the as-synthesized material.

Figure 10: The $\mathrm{Ce} \mathrm{L}_{3}$-edge XANES spectrum from the ion-implanted $\mathrm{Ce}_{0.94} \mathrm{Ti}_{2} \mathrm{O}_{6-\delta}$ material that was slow cooled from $1325^{\circ} \mathrm{C}$ to $\mathrm{RT}$ is shown and is compared to the corresponding spectrum from the as-synthesized material.

Figure 11: : The Ti K-edge XANES spectrum from the ion-implanted $\mathrm{Ce}_{0.94} \mathrm{Ti}_{2} \mathrm{O}_{6-\delta}$ material that was slow cooled from $1325^{\circ} \mathrm{C}$ to $\mathrm{RT}$ is shown and is compared to the corresponding spectrum from the as-synthesized material. The changes observed in the spectrum from the ion-implanted material when compared to the spectrum from the assynthesized material are indicated by arrows. The observed increase in the pre-edge peak intensity and decrease in the energy and intensity of the main-edge features is indicative a decrease in the average local coordination number of $\mathrm{Ti}$. 
Figures:

Figure 1:

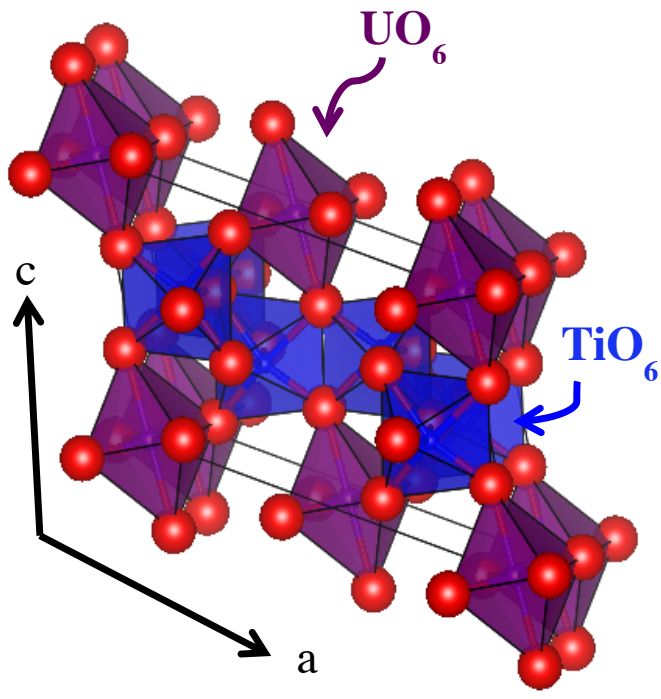


Figure 2:

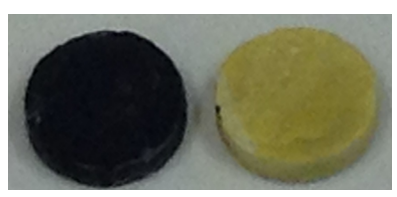




\section{Figure 3:}
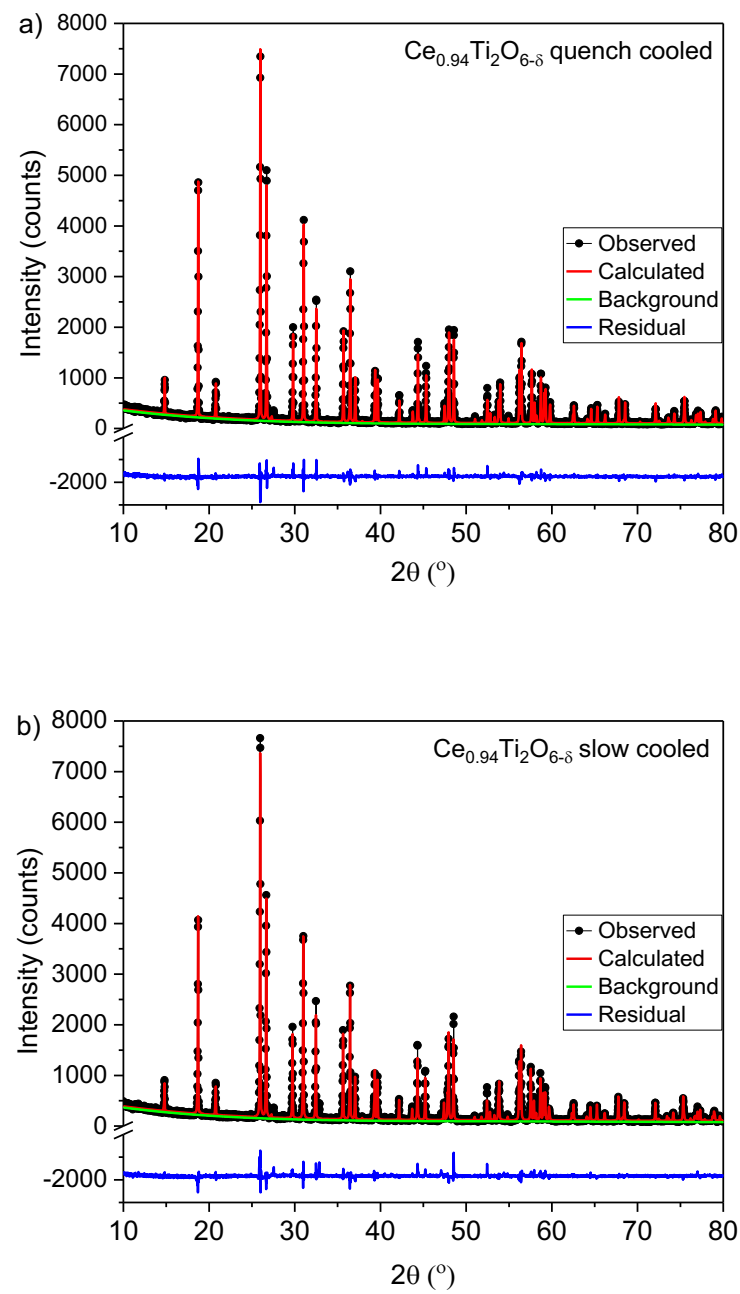
Figure 4:
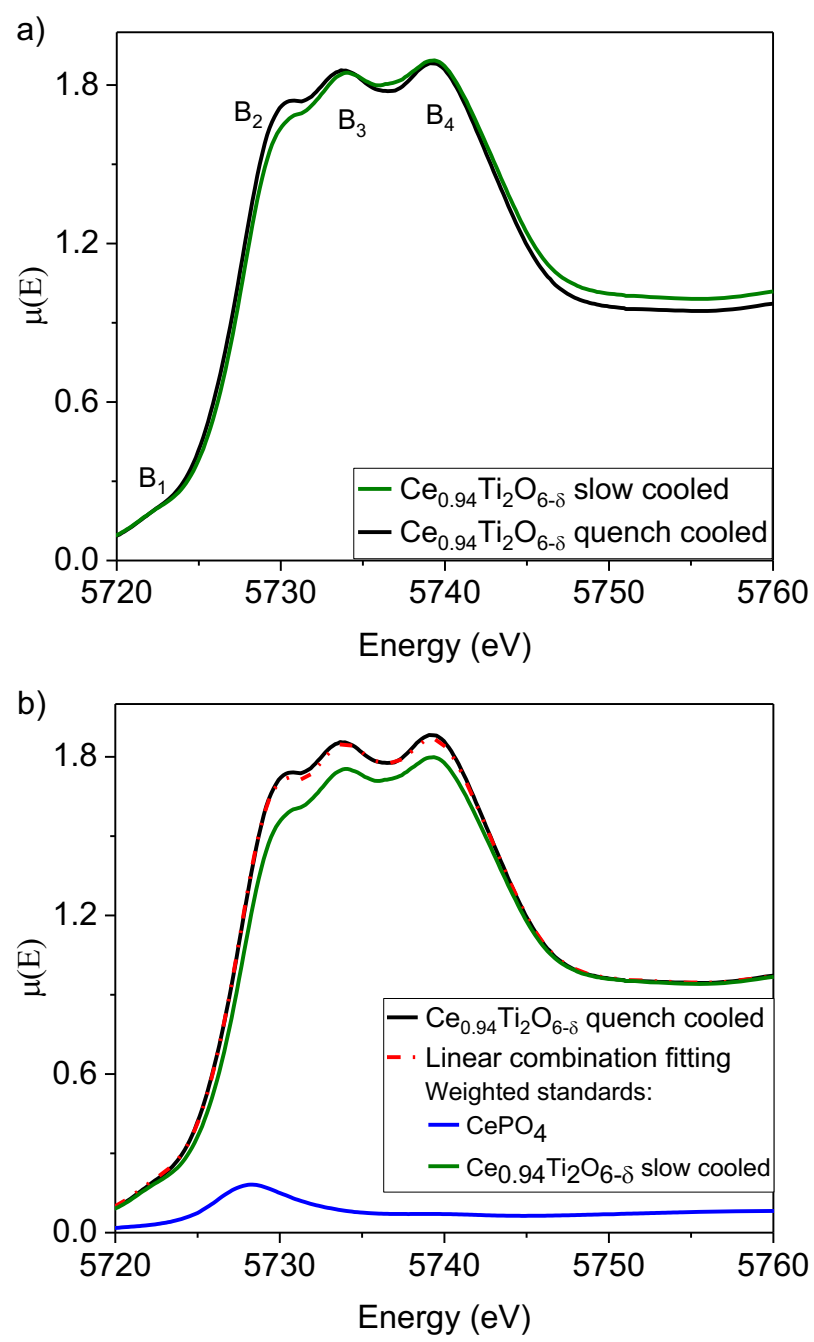


\section{Figure 5:}
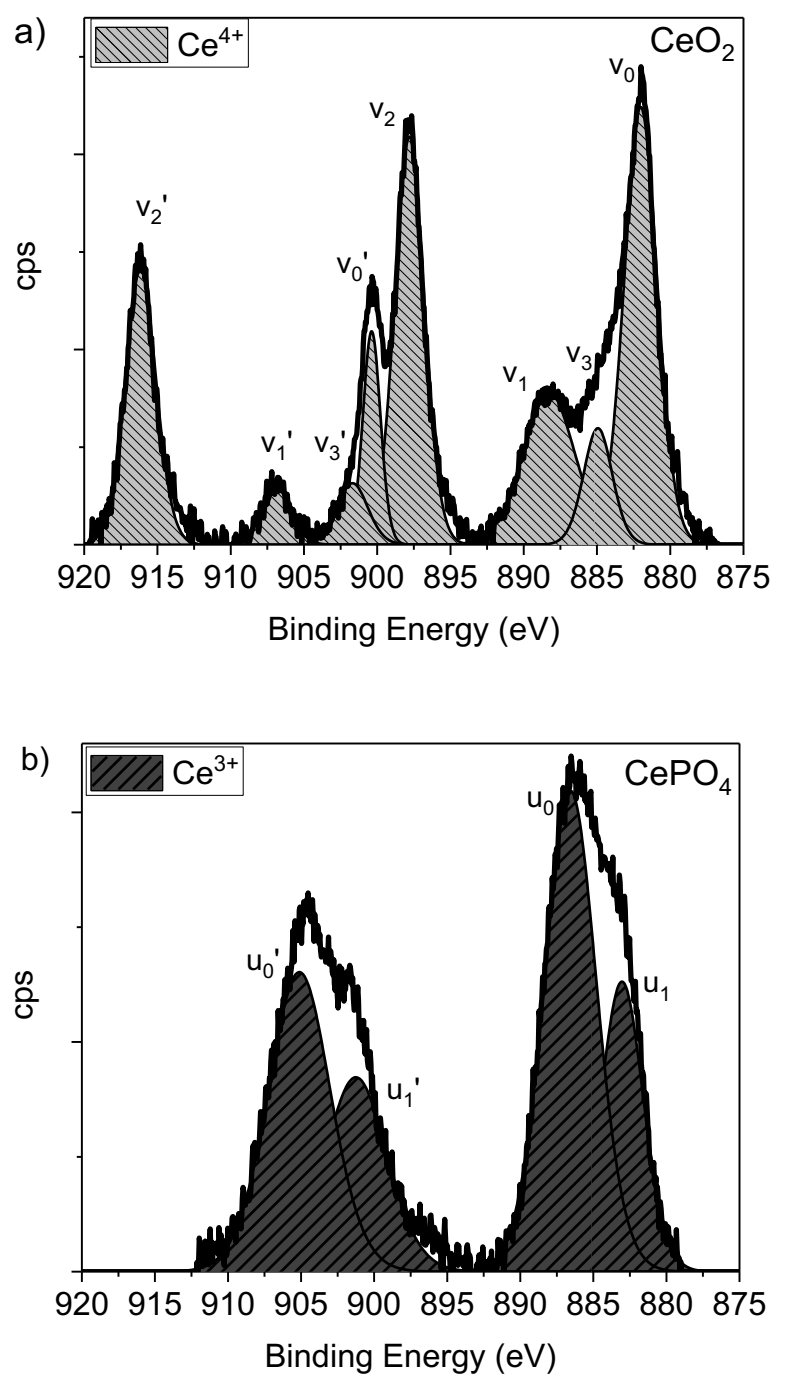


\section{Figure 6:}

Figure 7:

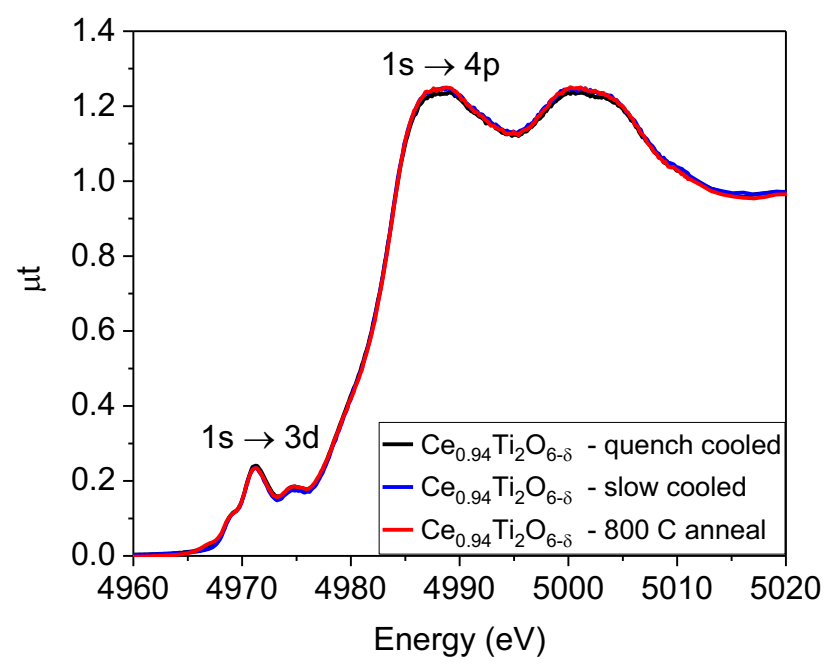


Figure 8:

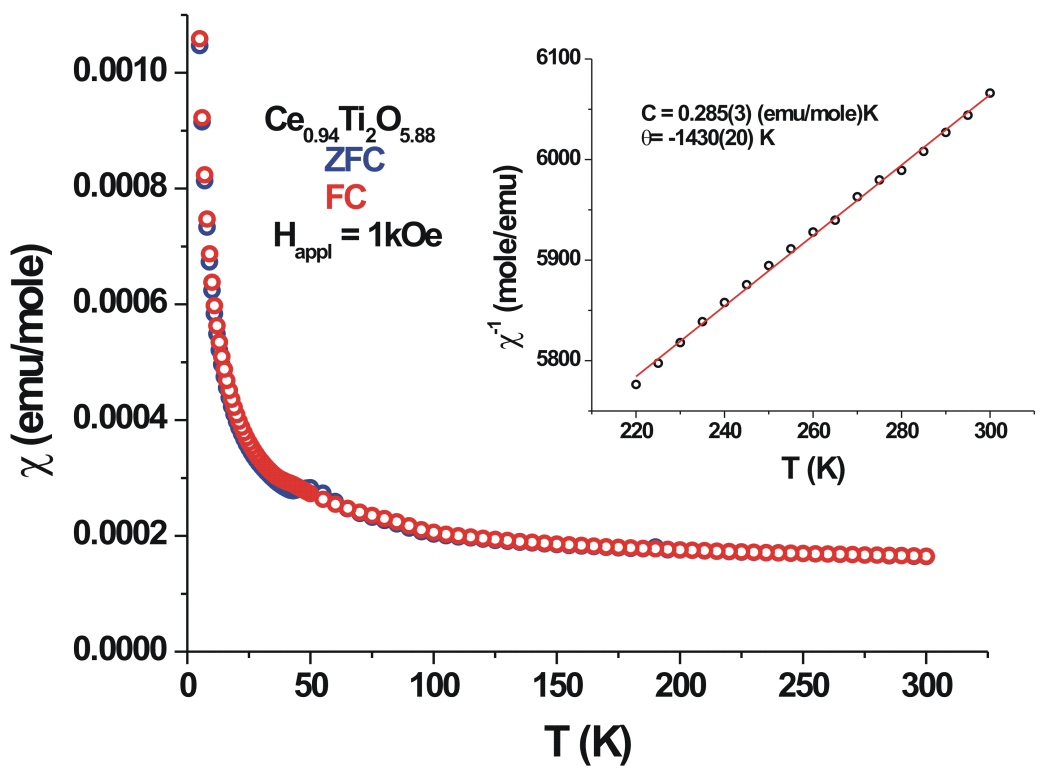




\section{Figure 9:}
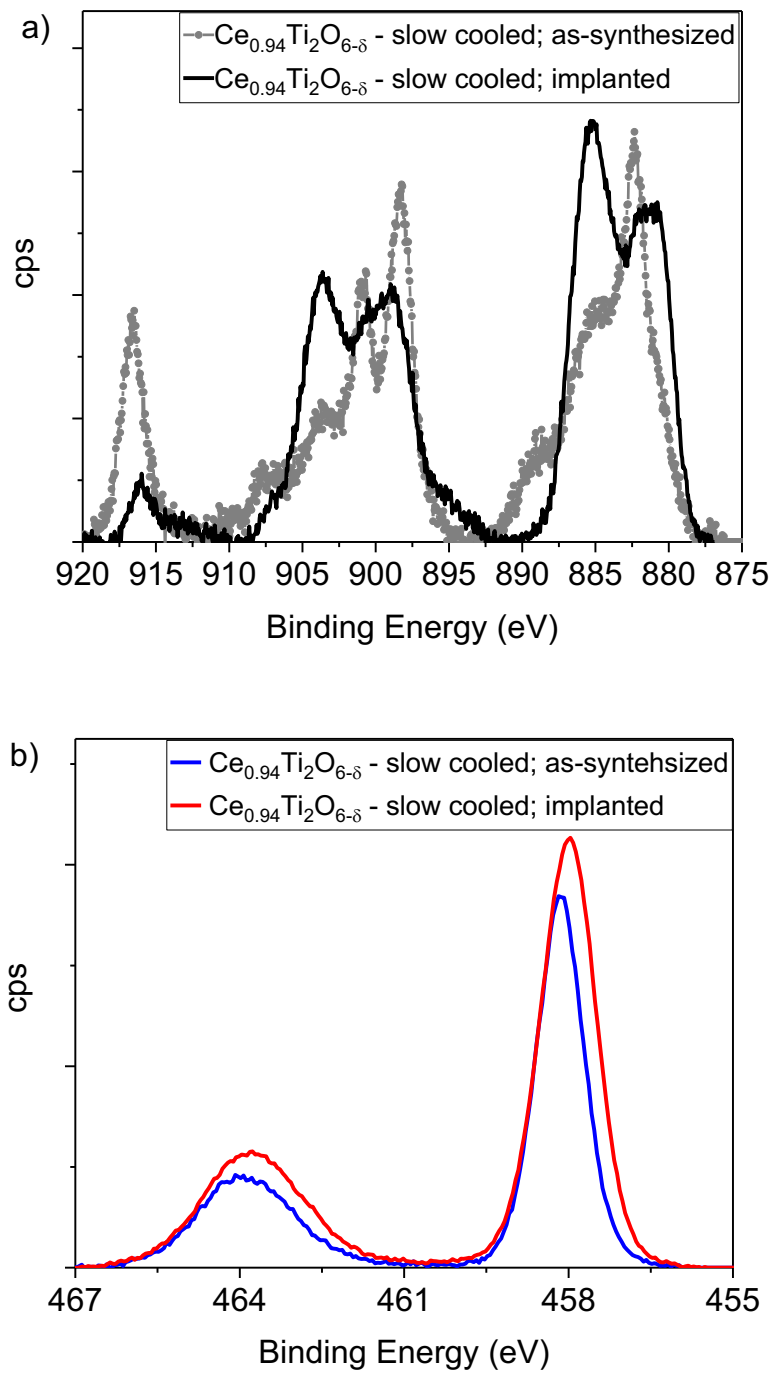
Figure 10:

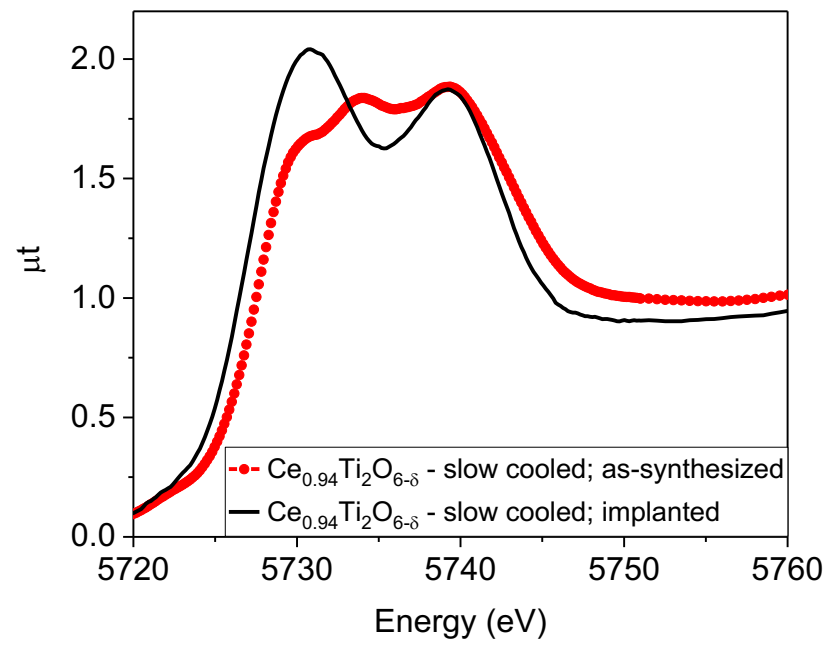




\section{Figure 11:}

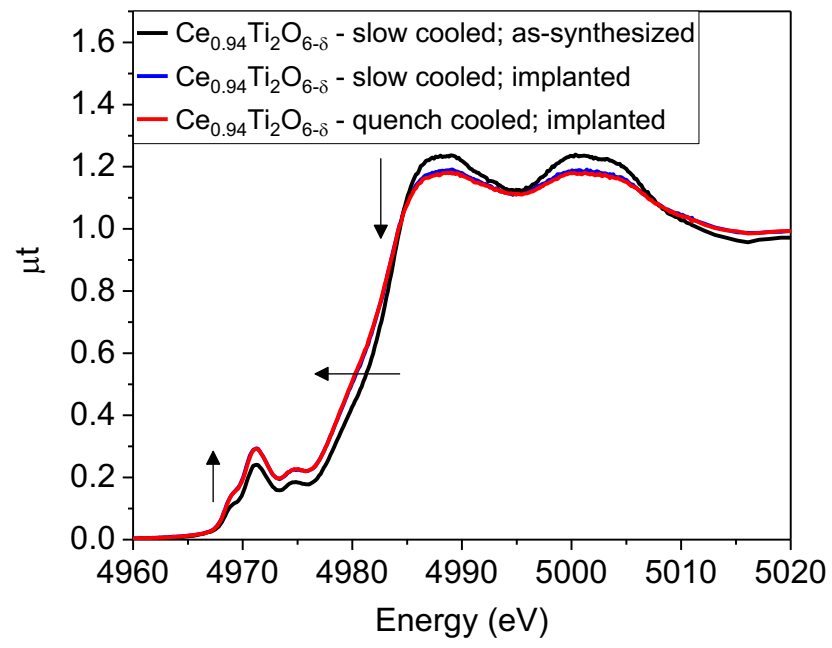

